\title{
RELAÇÕES CÁlCIO, MAGNÉSIO E POTÁSSIO SOBRE A PRODUÇÃO DE MATÉRIA SECA DE MILHO.
}

\section{Carlos Alberto Costa VELOSO(1); Francisco Ronaldo Sarmanho de SOUZA ${ }^{(2)}$; Walcilene Lacerda Matos PEREIRA ${ }^{(3)}$; Adna Rose de Morais TENÓRIO ${ }^{(3)}$.}

\begin{abstract}
RESUMO - O presente estudo teve o objetivo de avaliar o equilibrio $\mathrm{Ca} / \mathrm{Mg}$ na correção da acidez do solo e medir o efeito da aplicação do potássio sobre a produção de matéria seca do milho, num experimento conduzido sob casa de vegetação em vasos de plástico com Latossolo Amarelo, álico, distrófico. $\mathrm{O}$ delineamento experimental utilizado foi em blocos ao acaso, em esquema fatorial $(4 \mathrm{x}$ 3), com quatro repetições. Os tratamentos constituíram de quatro equilibrios em \% de $\mathrm{Ca}$ e $\mathrm{Mg}$ $(100 / 0 ; 75 / 25 ; 50 / 50 ;$ e $25 / 75)$ e três doses de potássio $\left(0 ; 100\right.$ e $200 \mathrm{mg} \mathrm{kg}^{-1}$ de terra) na forma de cloreto de potássio. A aplicação do corretivo sob a forma de reagentes puros (carbonato de cálcio e carbonato de magnésio) foi realizada 21 dias antes do plantio, e os nutrientes foram aplicados na forma de solução. A colheita do experimento foi realizada aos 45 dias após o plantio. Determinaramse as produções de matéria seca e os teores de $\mathrm{K}, \mathrm{Ca}$ e $\mathrm{Mg}$. Os resultados demonstraram que, as produções máximas foram obtidas quando o $\mathrm{pH}$ foi de 6,$3 ; 0$ teor de calcio de $27,5 \mathrm{mmol} \mathrm{dm}^{-3}$; o teor de magnésio de $18,0 \mathrm{mmol}_{\mathrm{c}} \mathrm{dm}^{-3}$; a relação $(\mathrm{Ca}+\mathrm{Mg}) / \mathrm{K}$ igual a 19,8 e a relaçào $\mathrm{Ca} / \mathrm{Mg}$ no corretivo foi de $1,1 / 1$. A relação $\mathrm{Ca} / \mathrm{Mg}$ no solo foi um dos principais fatores que alterou a produção. As doses de potássio proporcionou aumento quadrático e significativo, independente das doses de calagem empregadas e das relações $\mathrm{Ca} / \mathrm{Mg}$ utilizadas. Doses crescentes de potássio, reduziu o acúmulo do magnésio na parte aérea das plantas de milho.
\end{abstract}

Palavras-chave: Zea mays, calagem, solo ácido, macronutrientes.

\section{Effect of Calcium, Magnesium and Potassium Rate in the Production of Dry Matter of Corn}

ABSTRACT - The effect of calcium and magnesium rate in the correction of soil acidity and the effect of potassium on the production of dry matter of corn were assessed under greenhouse conditions. Corn seedlings were grown in plastic pots of soil Oxisol (Yellow Latosol dystrophic) in a randomised blocks and factorial design ( $4 \times 3$ ) with four replications. Four calcium and magnesium rates $(100 / 0 ; 75 / 25 ; 50 / 50$ and $25 / 75)$ and three potassium levels $(0 ; 100$ and 200 $\mathrm{mg} \mathrm{dm}{ }^{-1}$ of soil) as potassium chloride were tested. Pure reagents as corrective (calcium and magnesium carbonate) were incorporated into the soil 21 days before planting and micronutrients applied as solution. Cobs were harvested 45 days after planting. Production of dry matter as well as potassium, calcium and magnesium contents were determined. Maximal production was recorded when the following conditions were reached: $\mathrm{pH} 6.3,27.5 \mathrm{mmol}_{\mathrm{cm}}^{3}$ content, $18.0 \mathrm{mmol}_{\mathrm{cm}} \mathrm{dm}^{3}$ content, $\mathrm{Ca}+\mathrm{Mg} / \mathrm{K}$ rate equal to 19.8 and $\mathrm{Ca} / \mathrm{Mg}$ rate in the corrective equal to $1.1 / 1$. The $\mathrm{Ca} / \mathrm{Mg}$ rate was the main factor changing the production while crescent levels of potassium caused significantly increases in production, apart of liming and $\mathrm{Ca} / \mathrm{Mg}$ rate. Crescent levels of potassium decreased in magnesium accumulation in the foliage of corn plants.

Key-words: Zea mays, liming, soil acidity, macronutrients.

\section{INTRODUÇÃO}

A área de cultivo de milho no Brasil praticamente não se alterou nos últimos dez anos, situando-se ao redor de 14,0 milhões de hectares. A produtividade ainda é baixa, mas vem crescendo gradativamente. Neste

\footnotetext{
${ }^{1}$ Eng $^{\circ}$ Agro $^{\circ}$, Dr., Embrapa Amazônia Oriental, Caixa Postal 48, CEP 66.095-100. Belém-PA. ${ }^{2}$ Eng $^{\mathrm{o}} \mathrm{Agr}^{\circ}$, MSc., Embrapa Amazônia Oriental, Caixa Postal 48, CEP 66.095-100. Belém-PA. ${ }^{3}$ Eng $^{\mathrm{O}} \mathrm{Agr}^{\mathrm{o}}$, Estudante do Curso de Pós-Graduação em Agronomia da Faculdade de Ciências Agrárias do Pará, Caixa Postal 917, CEP 66.077-530, Belém-PA.
} 
período, passou da média de 1.868 para $2.429 \mathrm{~kg} / \mathrm{ha}$ (IBGE, 1997). A baixa produtividade brasileira está relacionada ao baixo nível tecnológico empregado na produção, tais como, uso de sementes de espécies não melhoradas, adubação inadequada e baixo uso de defensivos.

A área cultivada com milho no Estado do Pará não pode ser considerada expressiva, se forem levadas em conta as condições de solo, a topografia e o clima para o desenvolvimento da cultura. Em nível nacional, o Pará ocupa o décimo quarto lugar em área, mas em produção e em produtividade está em décimo lugar, na região norte ocupa o primeiro lugar. Em 1997, na Região Norte, a área cultivada com a cultura do milho foi da ordem de 626.189 ha, com uma produção de $974.857 \mathrm{t}$ e um rendimento médio de $1.557 \mathrm{~kg} / \mathrm{ha}$ (IBGE, 1997).

No Estado do Pará, a área cultivada com milho em 1997 foi de 317.679 ha e uma produção da ordem de $432.521 \mathrm{t}$, para um rendimento médio de $1.362 \mathrm{~kg} / \mathrm{ha}$.

A cultura do milho tem sido uma excelente atividade para o produtor rural, nos programas de manejo e recuperação de solos, como alternativa de produção para abastecer a agroindústria e como uso na alimentação humana e animal. Entretanto, os atuais sistemas utilizados para a cultura do milho no Estado do Pará têm contribuido para a sua baixa produtividade e sustentabilidade. As principais áreas de produção dessa cultura estão localizadas em regiões onde predominam os Latossolos caracterizados pela elevada acidez, baixa saturação por bases e, como principal conseqüência, pode ocorrer concentrações de alumínio e manganês em níveis tóxicos para o cultivo do milho (Falesi, 1972).

Para o sucesso do cultivo do milho, a correção da acidez é fundamental, pelos efeitos que causa na neutralização de elementos tóxicos, como alumínio e o manganês, na elevação do $\mathrm{pH}$ do solo, no aumento da disponibilidade de nutrientes e na melhoria do ambiente radicular para o desenvolvimento de microrganismos, como fungos micorrizicos. Pode-se fazer calagem usando-se unicamente o cálcio como elemento na correção da acidez e neutralização do alumínio trocável. Entretanto, adicionando-se somente esse elemento, haveria desequilibrio entre cálcio e magnésio, prejudicando o crescimento das plantas. Dessa maneira, se forem adicionadas doses de calcário, com $\mathrm{Ca}$ e $\mathrm{Mg}$, em proporções adequadas, para melhorar as condições de equilíbrio desses nutrientes no solo, o que consequentemente favorecerá o desenvolvimento das plantas.

$$
\text { Alguns trabalhos têm }
$$
demonstrado a grande importância das relações $(\mathrm{Ca}+\mathrm{Mg}) / \mathrm{K}, \mathrm{Ca} / \mathrm{K}$ e $\mathrm{Ca} / \mathrm{Mg}$ sobre a disponibilidade de nutrientes para as plantas (Morais \& Cabala, 1971). Entretanto, são escassos os estudos sobre essas relaçōes em solos da região amazônica. Assim, o emprego de corretivos e de fertilizantes que forneçam esses 
nutrientes sem o conhecimento da melhor relação entre os nutrientes, poderá resultar em produções insatisfatórias.

Desse modo, o objetivo deste trabalho foi avaliar o equilíbrio $\mathrm{Ca} / \mathrm{Mg}$ na correção da acidez do solo e medir o efeito da aplicação do potássio sobre a produção de matéria seca do milho em casa de vegetação.

\section{MATERIAL E MÉTODOS}

O experimento foi instalado em casa de vegetação da Embrapa Amazonia Oriental, no período de agosto a dezembro de 1997.

O solo utilizado foi um Latossolo Amarelo, álico, distrófico, textura argilosa, classificado segundo Oliveira et al. (1992). O solo foi coletado em área não desbravada do município de Paragominas, PA, na camada de $0-20 \mathrm{~cm}$ de profundidade. As carac-terísticas químicas e físicas do solo encontram-se na Tabela 1.

Para elevar o indice de saturação por base, fez-se calagem com $\mathrm{CaCO}_{3}$ e $\mathrm{MgCO}_{3}$ P.A. na proporção de 3:1, 30 dias antes da aplicação dos tratamentos. A correção da acidez do solo foi feita visando aumentar a saturação por base, ao valor de $70 \%$, seguindo recomendação técnica para milho, em solos quando a saturação por bases é inferior a $60 \%$ (Raij, 1991).

O solo recebeu a seguinte adubação básica nas seguintes doses (mg. $\mathrm{kg}^{-1}$ ): 200 de N, na forma de uréia e sulfato de amônio; 200 de P, na forma de superfosfato triplo; 48 de $\mathrm{S}$, na forma sulfato de amônio; 0,5 de B na forma de ácido bórico; 1,5 de $\mathrm{Cu}$ na forma de sulfato de cobre; 1,5 de Mn na forma de sulfato de manganês; e 5,0 de $\mathrm{Zn}$ na forma de sulfato de zinco. Estas doses foram adaptadas de Malavolta (1980) para experimentos em casa de vegetação.

$\mathrm{O}$ delineamento experimental utilizado foi blocos ao acaso, em esquema fatorial $4 \times 3$, com quatro repetições. A unidade experimental foi constituída por um vaso, com $3,0 \mathrm{~kg}$ de solo e contendo quatro plantas de milho da cultivar BR01.

Os tratamentos consistiram de quatro equilibrios em \% de $\mathrm{Ca}$ e $\mathrm{Mg}$ $(100 / 0 ; 75 / 25 ; 50 / 50$; e $25 / 75)$ e três doses de potássio $(0 ; 100$ e $200 \mathrm{mg} . \mathrm{kg}$ ${ }^{1}$ de terra) na forma de cloreto de potássio.

A aplicacão dos nutrientes foi feita com solução nutritiva, após as plantas terem se estabelecido. A exceção do fósforo que foi

Tabela 1. Características químicas e físicas de amostras do Latossolo Amarelo ${ }^{1}$

\begin{tabular}{|c|c|c|c|c|c|c|c|c|c|c|c|}
\hline $\begin{array}{c}\mathrm{pH} \\
(\mathrm{H} 2 \mathrm{O})\end{array}$ & M.O. & $P$ & $\mathrm{Ca}$ & $\mathrm{Mg}$ & $\mathrm{K}$ & Al & $\mathrm{H}+\mathrm{Al}$ & $\begin{array}{c}\text { Areia } \\
\text { grossa }\end{array}$ & $\begin{array}{l}\text { Areia } \\
\text { fina }\end{array}$ & Silte & Argila \\
\hline & g. $\mathrm{kg}-1$ & $\mathrm{mg} \cdot \mathrm{kg}-1$ & & -1 & nol & $n-3$ & & & _ & $\mathrm{kg}$ & - \\
\hline 5,2 & 15,3 & 1,0 & 16,5 & 5,0 & 0,4 & 9,0 & 48,0 & 10,0 & 20,0 & 230,0 & 740,0 \\
\hline
\end{tabular}

'Análises realizadas no Laboratório de Solos da Embrapa Amazônia Oriental. 
previamente incorporado ao solo. A aplicação de nitrogênio e potássio foi feita $1 / 3,10$ dias após o plantio, 1/3 aos 20 dias após plantio e $1 / 3$ aos 40 dias após o plantio. Os demais nutrientes foram aplicados de uma única vez.

A irrigação foi feita diariamente, utilizando-se água destilada e mantendo-se o teor de umidade próximo da capacidade de campo.

A colheita das plantas foi realizada 45 dias após o plantio. Foram separados a parte aérea e raizes, sendo a secagem a $70^{\circ} \mathrm{C}$ realizada em estufa de circulação forçada de ar, até atingir peso constante. As raizes foram devidamente lavadas para separa-las das particulas de solo, sendo posteriormente secas em estufa. O material vegetal foi pesado, moído e submetido à análise química, para determinação dos teores de $\mathrm{K}, \mathrm{Ca} \mathrm{e} \mathrm{Mg}$.

Para a determinação dos teores de potássio, cálcio e magnésio foram obtidos por meio de digestão nítricoperclórica e posterior determinação no extrato. $\mathrm{O}$ potássio foi determinado por fotometria de chama, o cálcio e o magnésio por espectrofotometria de absorção atômica, conforme metodologia descrita por Malavolta et al. (1989).

A partir dos valores de produção de matéria seca da parte aérea, raizes e da planta, bem como os teores de nutrientes na parte aérea, efetuaram-se as análises da variância segundo Pimentel Gomes (1987). As médias dos tratamentos foram comparadas pelo teste de Tukey, ao nível de significância de $5 \%$ de probabilidade.
Foram ajustadas equações de regressão, para todas as variáveis estudadas, em função das doses de potássio. As análises foram realizadas utilizando-se o programa estatístico SANEST.

\section{RESULTADOS E DISCUSSÃO}

\section{Produção de matéria seca}

A produção de matéria seca da parte aérea, raizes e planta inteira, dos vários tratamentos estudados, encontram-se na Tabela 2.

A produção de matéria seca foi afetada pelos diferentes equilibrios, verificando-se que com o uso de $50 \%$ de cálcio e $50 \%$ de magnésio (50/50), foram obtidos os maiores valores na parte aérea. Na matéria seca das raizes e planta inteira, encontrou-se efeitos significativo para os tratamentos com uso de $25 \%$ de cálcio e $75 \%$ de magnésio.

As doses de potássio propiciaram também diferenças significativas na produção de matéria seca, com a dose de $100 \mathrm{mg} . \mathrm{kg}^{-1}$, apresentando os melhores resultados, na parte aérea, raizes e planta inteira.

A produção de matéria seca da parte aérea (MSPA) foi afetada pelas variações das relações $\mathrm{Ca}: \mathrm{Mg}$ testadas (Fig. 1). Comportamento similar tiveram as outras características do crescimento, indicando pouca sensibilidade da cultura às variações nas relações $\mathrm{Ca}: \mathrm{Mg}$ do substrato. Os resultados evidenciam que a quantidade de cada cátion $\left(\mathrm{Ca}^{++}\right.$e $\left.\mathrm{Mg}^{++}\right)$é mais importante que suas próprias relações no solo. Isso possibilita uma maior 
Tabela 2. Produção média de matéria seca (g/vaso) do milho em função dos tratamentos, aos 45 dias de idade (média de quatro repetições).

\begin{tabular}{|c|c|c|c|c|}
\hline \multirow{2}{*}{$\begin{array}{l}\text { Equilibrios } \\
\mathrm{Ca} / \mathrm{Mg}\end{array}$} & \multirow{2}{*}{$\begin{array}{l}\text { Doses de K } \\
\text { (mg.kg-1) }\end{array}$} & \multicolumn{3}{|c|}{ Produção de matéria seca } \\
\hline & & Parte aérea & Raízes & Total \\
\hline & & \multicolumn{3}{|c|}{ 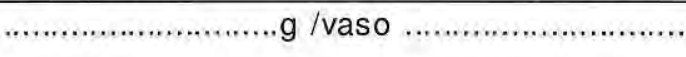 } \\
\hline $100 / 0$ & 0 & $35,58 a b$ & 6,80 defg & $42,38 \mathrm{~cd}$ \\
\hline $100 / 0$ & 100 & $31,10 \mathrm{cde}$ & 8,04 cde & $39,13 d$ \\
\hline $100 / 0$ & 200 & $20,67 \mathrm{~g}$ & 7,55 cdef & $28,23 \uparrow$ \\
\hline $75 / 25$ & 0 & 27,52 ef & $6,03 \mathrm{fg}$ & $33,59 \mathrm{e}$ \\
\hline $75 / 25$ & 100. & $30,63 \mathrm{de}$ & $8,93 \mathrm{~cd}$ & $39,56 \mathrm{~d}$ \\
\hline $75 / 25$ & 200 & $24,56 \mathrm{fg}$ & 6,97 defg & 31,53 ef \\
\hline $50 / 50$ & 0 & $34,49 \mathrm{bcd}$ & 6,61 efg & $41,09 \mathrm{~d}$ \\
\hline $50 / 50$ & 100 & 39,52 a & $9,20 \mathrm{c}$ & $48,71 \mathrm{ab}$ \\
\hline $50 / 50$ & 200 & $35,27 \mathrm{bc}$ & $11,56 \mathrm{~b}$ & $46,83 \mathrm{bc}$ \\
\hline $25 / 75$ & 0 & $35,00 \mathrm{bc}$ & $5,32 \mathrm{~g}$ & $40,32 d$ \\
\hline $25 / 75$ & 100 & $36,48 \mathrm{ab}$ & 15,68 a & $52,16 \mathrm{a}$ \\
\hline $25 / 75$ & 200 & 31,44 cde & $16,71 \mathrm{a}$ & $48,14 a b$ \\
\hline
\end{tabular}

(1) Médias seguidas pela mesma letra nas colunas, não apresentam diferença significativa, ao nível de $5 \%$ de probabilidade, pelo teste de Tukey.

liberdade na escolha do calcário a ser utilizado, para o milho.

Pela análise de variância verificou-se efeito para tratamentos e interações equilibrios de cálcio/ magnésio e doses de potássio $(\mathrm{P}<0,05)$. Em vista disso fez-se o desdobramento dos graus de liberdade de equibrios de cálcio/magnésio $x$ doses de potássio, que indicou que em todos os casos que a dose de 100 $\mathrm{mg} \cdot \mathrm{kg}^{-1}$ de potássio proporcionou maior produção de matéria seca em relação as doses de $\mathrm{K}$. A correção da acidez, mesmo que em níveis muito abaixo daqueles recomendados para a cultura, foi responsável pela diferença. A produção obtida com metade da maior dose de cálcio como $\mathrm{CaCO}_{3}$ se aproximou daquelas obtidas com a elevação do índice de saturação por bases em $70 \%$, havendo diferença quando comparados aos demais tratamentos do equilíbrio $\mathrm{Ca} / \mathrm{Mg}$.

A medida que foi diminuído o teor de cálcio nos equilíbrios, foi aumentado o teor de magnésio e observou-se valores de $\mathrm{pH}$ mais elevados (Tab. 3).

Nas Figuras 1, 2 e 3, são apresentados o ajuste destes dados de produção de matéria seca em função 
Tabela 3. Teores médios de cálcio e magnésio em $\left(\mathrm{mmol}_{\mathrm{c}} \mathrm{dm}^{-3}\right)$ e valores de $\mathrm{pH}$, antes do plantio, aos 30 dias da incubação.

\begin{tabular}{cccc}
\hline Equilíbrios & Cálcio & Magnésio & $\mathrm{PH}$ \\
\hline$\% \mathrm{Ca} / \% \mathrm{Mg}$ & $-\cdots$ & \\
$100 / 0$ & 36,0 & 5,0 & 6,2 \\
$75 / 25$ & 31,0 & 14,0 & 6,3 \\
$50 / 50$ & 25,0 & 22,0 & 6,4 \\
$25 / 75$ & 18,0 & 31,0 & 6,5 \\
\hline
\end{tabular}

da relação $\mathrm{Ca} / \mathrm{Mg}$ e doses de potássio. Analisando-se essas figuras, verificase que, à medida que se aumentou a percentagem de magnésio nos equilibrios, houve aumento da produção de matéria seca, ocorreu redução na produção de matéria seca com aumento das doses de potássio e, também com base na equação, para uma produção máxima o equilíbrio ótimo de $\mathrm{Ca} / \mathrm{Mg}$ no corretivo encontrado foi de $1,1 / 1$. Observa-se que os teores de cálcio e magnésio no solo são muito elevados, demonstrando efeito prejudicial de uma calagem excessiva. Os teores ótimos de cálcio e magnésio que propiciaram produções máximas, foram respectivamente 27,5 e $18,0 \mathrm{mmol}_{\mathrm{c}} \mathrm{dm}^{-3}$. Os valores ótimos de $\mathrm{pH}$ foi de 6,3 onde proporcionaram as produções máximas. Esse valor de $\mathrm{pH}$ encontra-se dentro da faixa recomendada por Laroche (1967) para esta cultura.

Pela análise de regressão, observou-se que as relações ótimas de $\mathrm{Ca} / \mathrm{Mg}$ no solo foi de 1,53 onde proporcionaram as produções máximas. De acordo com Sfredo (1976), para que não haja prejuizo na produção, a relação $\mathrm{Ca} / \mathrm{Mg}$ no solo deve ser maior que 0,5 . As relações ótimas de $(\mathrm{Ca}+\mathrm{Mg}) / \mathrm{K}$ do solo foi de 19,8. Segundo Mechlich, citado por Brigeno e Carvajal (1973), considera que quando a relação $(\mathrm{Ca}+$ $\mathrm{Mg}) / \mathrm{K}$ do solo for maior que 10 , tal relação deve ser considerada como valores baixos para o potássio. Quando a relação $\mathrm{Ca}: \mathrm{Mg}$ no solo aumentou de $1: 1$ para $4: 1$, decorrente do incremento da concentração do cálcio, ocorreu uma diminuição da matéria seca das raízes e na quantidade de magnésio acumulada nas raizes do milho

(Tab. 4).

\section{Acúmulo de cálcio, magnésio e potássio}

Quando a relação $\mathrm{K}: \mathrm{Mg}$ aumentou de $1: 1$ para $4: 1$, decorrente do incremento na concentração do potássio da solução externa, de 100 até 200 mg. $\mathrm{kg}^{-1}$, ocorreu diminuição na quantidade de magnésio acumulada nas raizes do milho. Igualmente, a quantidade de magnésio acumulada na parte aérea das plantas diminuiu significativamente com o aumento da relação $\mathrm{K}: \mathrm{Mg}$ (Tab. 4). Estes resultados concordam com os obtidos por Fonseca \& Meurer (1997) que constataram um efeito inibitório do potássio sobre os parâmetro cinéticos 


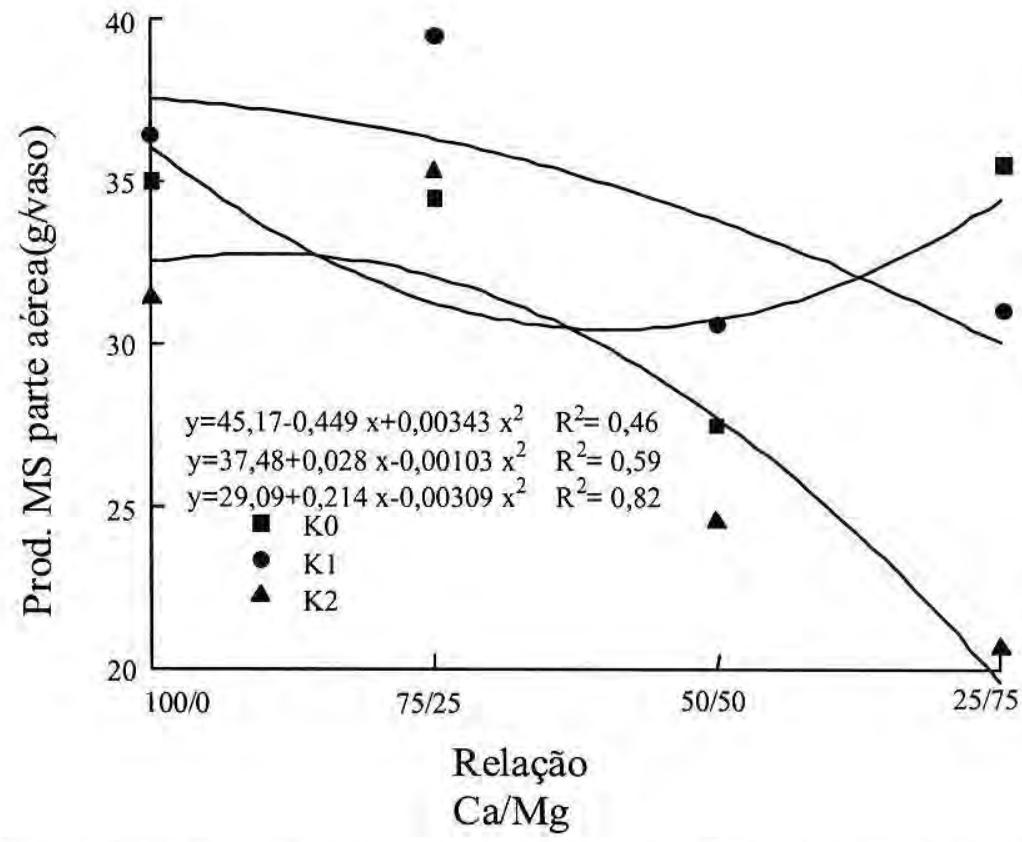

Figura 1. Produção de matéria seca da parte aérea ( $\mathrm{g} /$ vaso) em função da relação $\mathrm{Ca} / \mathrm{Mg}$.

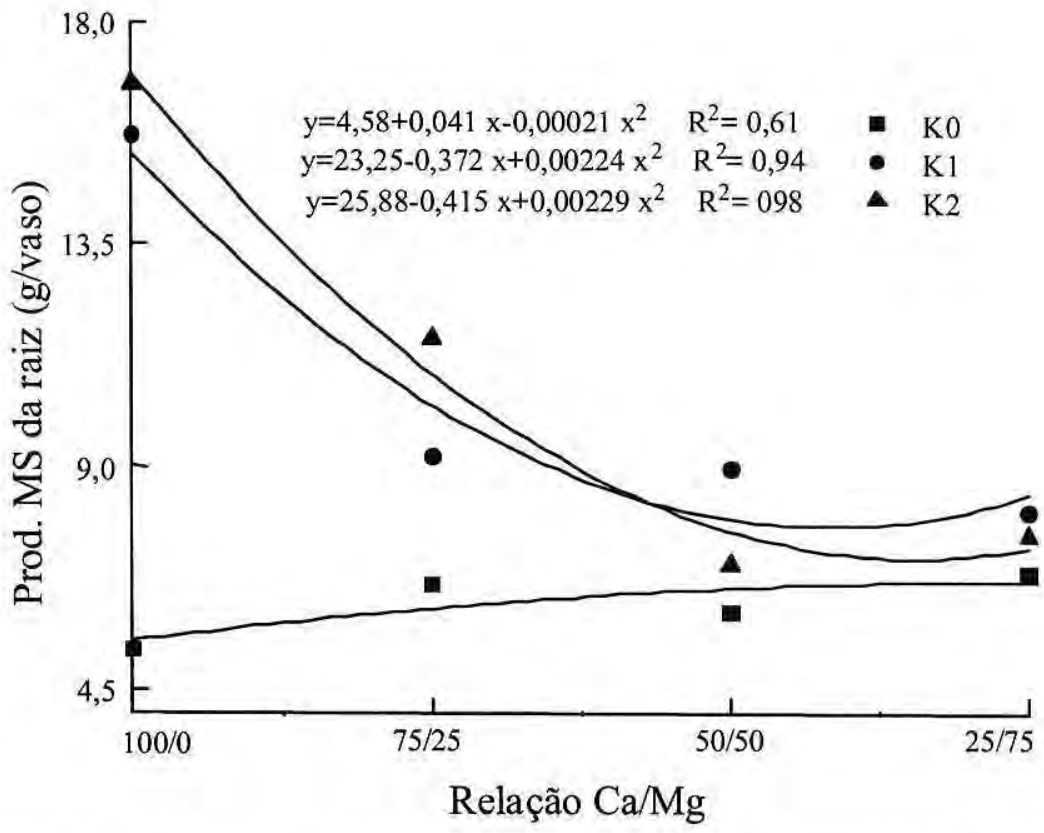

Figura 2. Produção de matéria seca da raiz ( $\mathrm{g} / \mathrm{vaso}$ ) em função da relação entre $\mathrm{Ca} / \mathrm{Mg}$. 


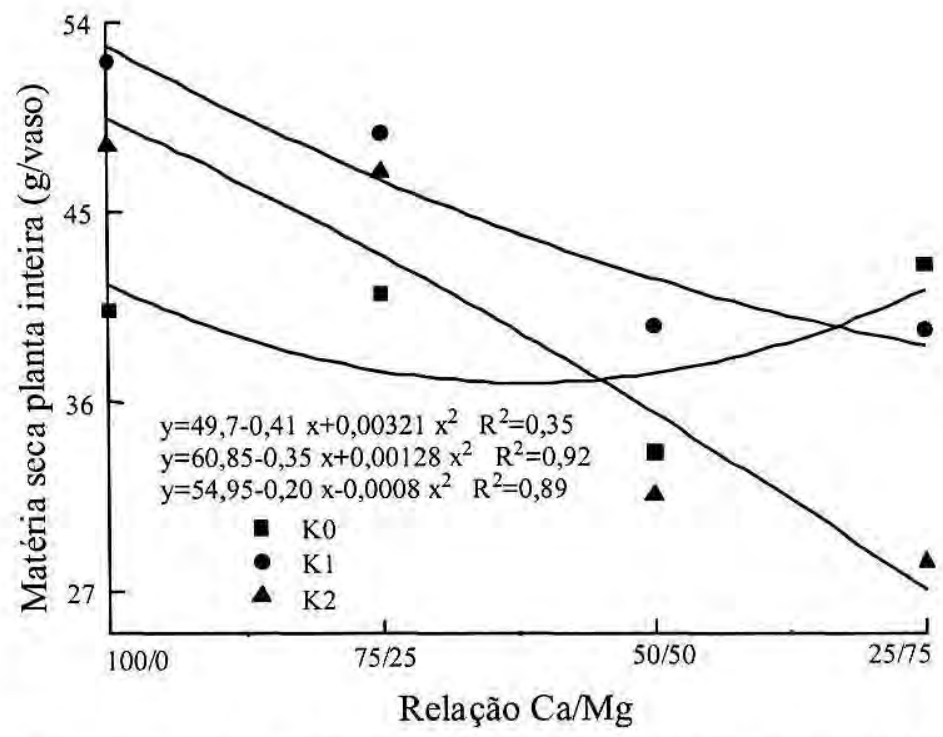

Figura 3. Matéria seca da planta inteira ( $\mathrm{g} / \mathrm{vaso})$ em função da relação entre $\mathrm{Ca} / \mathrm{Mg}$.

Tabela 4. Acúmulo de cálcio, magnésio e potássio ( $\mathrm{mg} / \mathrm{vaso}$ ) na parte aérea de plantas de milho aos 45 dias de idade afetado pelo equilibrio $\mathrm{Ca} / \mathrm{Mg}$ e doses de $\mathrm{K}$.

\begin{tabular}{|c|c|c|c|c|}
\hline \multirow[t]{2}{*}{ Equilibrios } & \multirow[t]{2}{*}{ Doses de K } & \multicolumn{3}{|c|}{ Nutrientes } \\
\hline & & Cálcio & Magnésio & Potássio \\
\hline $\mathrm{Ca} / \mathrm{Mg}$ & (mg.kg-1) & 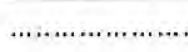 & .... mg /vaso & 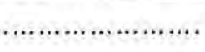 \\
\hline $100 / 0$ & 0 & $515,91 b$ & $185,02 i$ & $373,59 \mathrm{~h}$ \\
\hline $100 / 0$ & 100 & $528,80 \mathrm{a}$ & $264,35 \mathrm{~g}$ & $625,11+$ \\
\hline $100 / 0$ & 200 & $328,65 \mathrm{k}$ & $159,16 \mathrm{j}$ & $568,43 \mathrm{~g}$ \\
\hline $75 / 25$ & 0 & $357,76 \mathrm{j}$ & $162,37 \mathbf{j}$ & 299,97 j \\
\hline $75 / 25$ & 100 & $456,39 d$ & $373,69 d$ & $637,10 \mathrm{e}$ \\
\hline $75 / 25$ & 200 & $415,06 \mathrm{~g}$ & $245,60 \mathrm{~h}$ & $641,02 \mathrm{e}$ \\
\hline $50 / 50$ & 0 & $493,21 \mathrm{c}$ & $320,76 \mathrm{e}$ & $362,15 \mathrm{i}$ \\
\hline $50 / 50$ & 100 & $426,82 f$ & $387,30 \mathrm{c}$ & $731,12 \mathrm{c}$ \\
\hline $50 / 50$ & 200 & $451,46 d$ & $289,21 f$ & $1100,42 \mathrm{a}$ \\
\hline $25 / 75$ & 0 & $402,50 \mathrm{~h}$ & $406,00 \mathrm{~b}$ & $364,00 \mathrm{hi}$ \\
\hline $25 / 75$ & 100 & 445,06 e & $452,35 \mathrm{a}$ & $707,71 \mathrm{~d}$ \\
\hline $25 / 75$ & 200 & $377,28 \mathrm{i}$ & $245,23 \mathrm{~h}$ & $996,65 \mathrm{~b}$ \\
\hline
\end{tabular}

(1) Médias seguidas pela mesma letra nas colunas, não apresentam diferença significativa, ao nivel de $5 \%$ de probabilidade, pelo teste de Tukey. 
de absorção de $\mathrm{Mg}$ em plantas de milho, com acentuada redução do influxo liquido (Imax) do nutriente.

A literatura tem relatado a interferência do potássio na translocação do magnésio nas plantas (Schimanski, 1981; Hannaway et al., 1984). Estudos com magnésio radioativo tem sido utilizados na busca da explicação para o fenômeno. Entretanto, não há clareza sobre os exatos locais e mecanismos envolvidos na translocação. O retardamento no deslocamento radial do magnésio devido a sua alta interação com as cargas elétricas do apoplasto, principal caminho para seu deslocamento até o xilema, pode ser uma das causas da menor translocação (Walker \& Pitman, 1976; Schimanski, 1981). As caracteristicas físicas e os potenciais elétrico e químico do apoplasto promovem maior retenção de cátions divalentes como magnésio e cálcio, do que os monovalentes como o potássio (Mengel e Kirby, 1987; Clarkson, 1991; Marschner, 1993).

Os resultados obtidos neste experimento, confirmam os de Fonseca \& Meurer (1997) em solução nutritiva. O aumento do teor de potássio no solo, resultante da aplicação das doses de potássio, resultaram na diminuição do acumulo do magnésio na parte aérea das plantas de milho (Tab. 4 e Fig. 5). O incremento do teor do potássio trocável, modificou a relação $\mathrm{K}: \mathrm{Mg}$ na rizosfera, acarretando um efeito inibitório na absorção do magnésio, refletindo-se numa menor absorção do nutriente pelas raízes e menor translocação do mesmo para a parte aérea das plantas.

\section{CONCLUSÕES}

1. As produções máximas de matéria seca de milho foram obtidas quando o $\mathrm{pH}$ foi de 6,3 ; o teor de calcio de $27,5 \mathrm{mmol}_{\mathrm{c}} \mathrm{dm}^{-3}$; o teor de magnésio de $18,0 \mathrm{mmol}_{\mathrm{c}} \mathrm{dm}^{-3}$; a relação $(\mathrm{Ca}+\mathrm{Mg}) / \mathrm{K}$ igual a 19,8 e a relação $\mathrm{Ca} / \mathrm{Mg}$ no corretivo foi de $1,1 / 1$.

2. A relação $\mathrm{Ca} / \mathrm{Mg}$ no solo foi um dos principais fatores que alterou a produção de matéria seca de milho.

3. As doses de potássio proporcionaram aumento na produção de matéria seca, independente das doses de calagem empregadas e das relações $\mathrm{Ca} / \mathrm{Mg}$ utilizadas.

4. As doses crescentes de potássio, reduziram o acúmulo do magnésio na parte aérea das plantas de milho.

\section{Bibliografia citada}

Brigeno, J.A.; Carvajal, J. F. 1973. El equilibrio entre los metales alcalinos $y$ alcalinotérreos en el suelo, associado com la repuesta del cafeto al potássio. Turrialba, Turrialba, 23 (1): 56-71.

Clarkson, D.T, 1991. Root structure and sites of Ion uptake. In: Waisel, Y; Eshel, A.; Kafkafi, U. (eds.) Plant Roots: The hidden half. New York, Marcel Dakker. Chap.20, p.417-453.

Falesi, I.C. 1972. O estado atual dos conhecimentos sobre os solos da Amazônia Brasileira. In: Instituto de Pesquisa e Experimentação Agropecuária do Norte (Belém, PA) Zoneamento agricola da Amazônia ( $1^{\mathrm{a}}$ aproximação). Belém, p.17-67. (IPEAN. Boletim técnico, 54). 


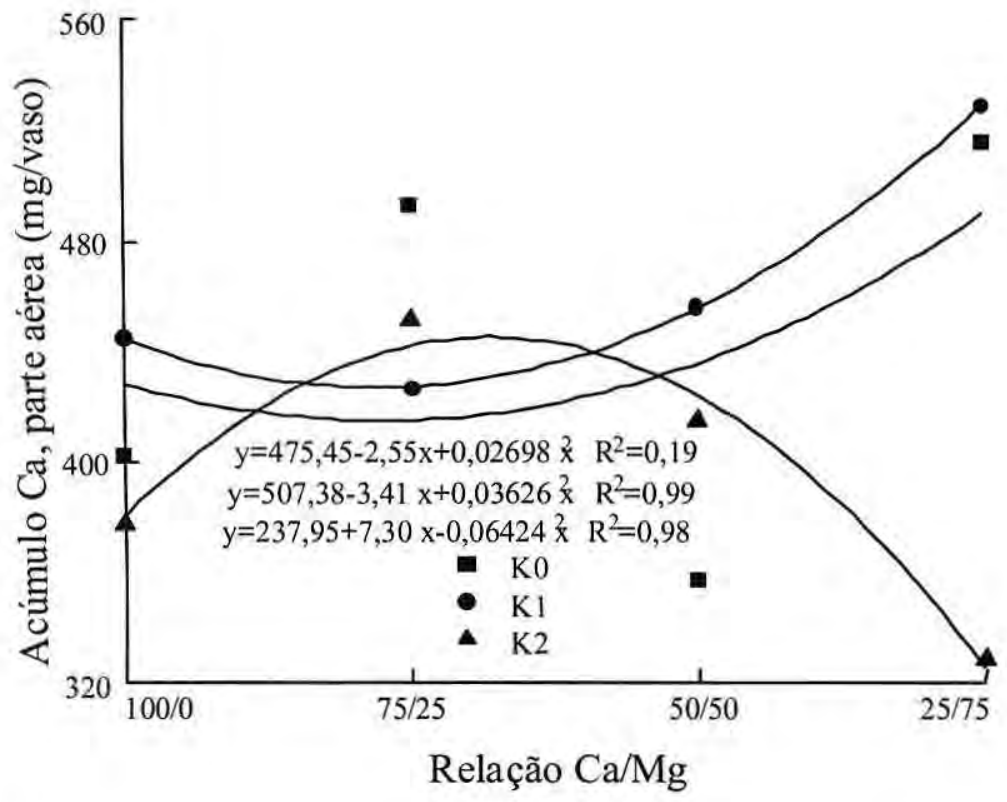

Figura 4. Acúmulo de cálcio (mg/vaso) na parte aérea de plantas de milho em função da relação entre $\mathrm{Ca} / \mathrm{Mg}$.

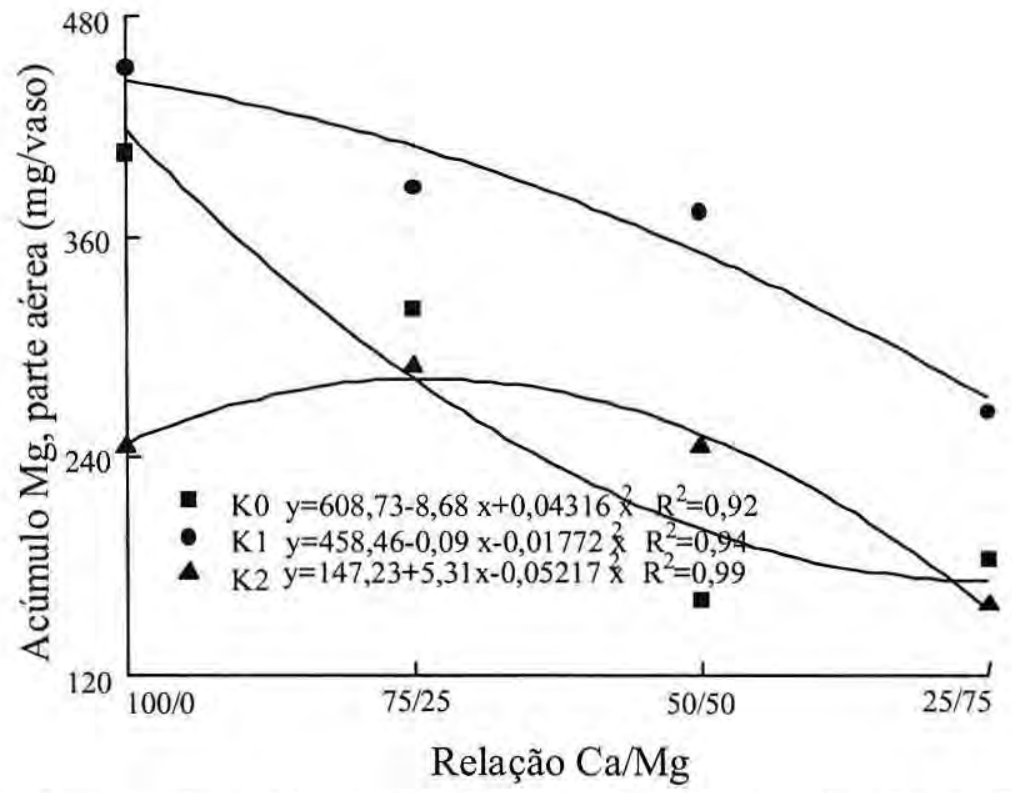

Figura 5. Acúmulo de magnésio ( $\mathrm{mg} / \mathrm{vaso}$ ) na parte aérea de plantas de milho em função da relação entre $\mathrm{Ca} / \mathrm{Mg}$. 


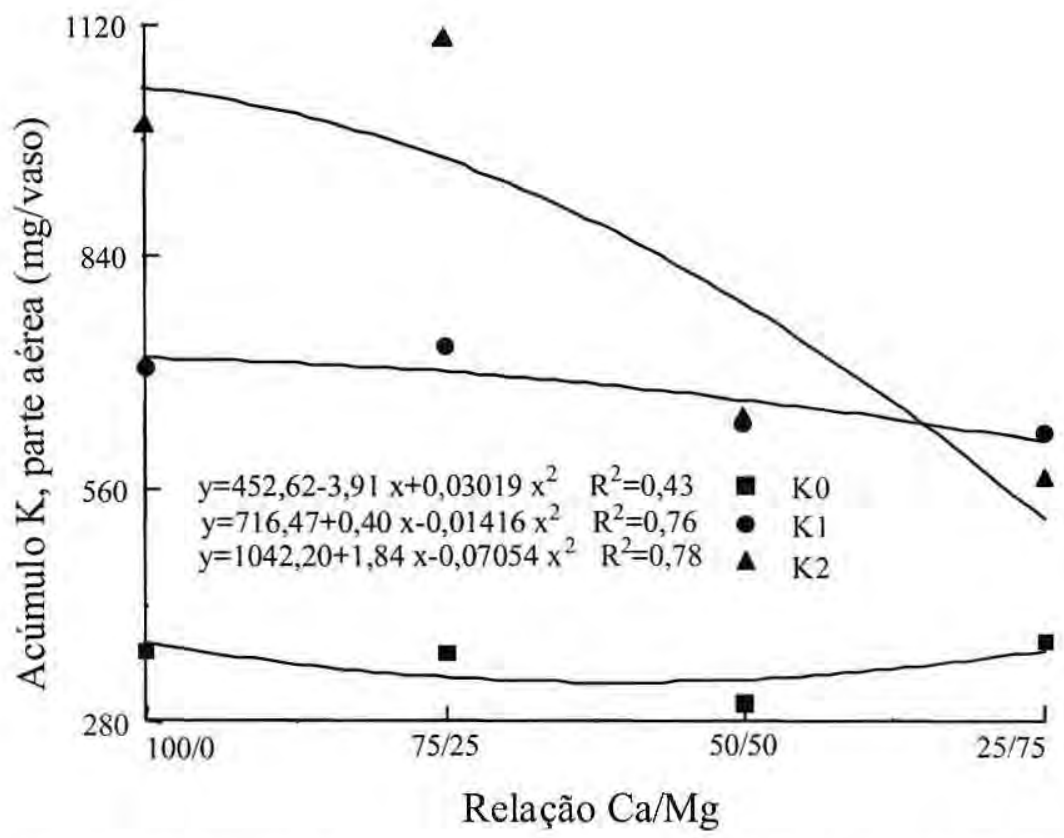

Figura 6. Acúmulo de potássio ( $\mathrm{mg} / \mathrm{vaso}$ ) na parte aérea de plantas de milho em função da relação entre $\mathrm{Ca} / \mathrm{Mg}$.

Fonseca, J.A.; Meurer, E.J. 1997. Inibição da absorção de magnésio pelo potássio em plântulas de milho em solução nutritiva. R.bras.Ci.Solo, Campinas, 21: 47-50.

Hannaway, D.B.; Leggett, J.E.; Bush, L.P.; Shuler, P.E. 1984. Magnesium (Mg) and Rubidium $(\mathrm{Rb})$ absorption by tall fescue. Journal of Plant Nutrition, Lexington, 7(7): 1127-1147.

IBGE. 1997. Levantamento sistemático da produção agricola. Anuário Estatístico do Brasil, Rio de Janeiro, 57: 3-32.

Laroche, F.A. 1967. Efeitos da calagem sobre o complexo de troca de um latossolo tropical e os teores de cátions absorvidos pelo tomate. Recife, SUDENE, Dv. Documentação, 80 p. (Brasil, SUDENE, Agricultura, 9).

Malavolta, E. 1980. Elementos de nutrição mineral de plantas. São Paulo, Ceres, $251 \mathrm{p}$.

Malavolta, E;; Vitti, G.C.; Oliveira, S.A. de. 1989. Avaliação do estado nutricional das plantas; princípios e aplicaçòes. Piracicaba, Associação Brasileira para a Pesquisa da Potassa e do Fosfato, 201p.

Marschner, H. 1993. Mineral nutrition of higher plants. 2.ed. London: Academic Press, $889 \mathrm{p}$.

Mengel, K. ; Kirkby, E.A. 1987. Principles of plant nutrition. 4.ed. Worblaufen-Bern: International Potash Institute, 687p.

Morais, F.I.O.; Cabala, F.P. 1971. Efeito dos equilíbrios entre cálcio, magnésio e potássio no crescimento do cacaueiro. Revista Theobroma, Ilhéus, I(3): 21-32.

Oliveira, J.B. de,; Jacomine, P.K.T.; Camargo, M.N. 1992. Classes gerais de solos do Brasil: guia auxiliar para seu reconhecimento. 2. ed. Jaboticabal: FUNEP, 201p.

Pimentel Gomes, F, 1987. Curso de estatistica experimental. 12 ed. Piracicaba, Nobel; 467p.

Raij, B. van. 1991. Fertilidade do solo e 
adubação, Piracicaba, Ceres, Potafos, $343 p$.

Schimansky, V.C. 1981. Der einflub einiger versuchsparameter auf das fluxverhalten von ${ }^{28} \mathrm{Mg}$ bei gerstenkeimpflanzen in hidrokulturversuchen, Landwirtsch, Forsch, 34: 154-165.

Sfredo, G.J. 1976. Efeito das relações Ca e Mg sobre o $\mathrm{pH}, \mathrm{Al}^{+++}, \mathrm{Ca}$, e $\mathrm{Mg}$ no solo e sobre a produção de matéria seca do sorgo (Sorghum bicolor(L) Moench. Viçosa, 61 p. Dissertação (Mestrado) Universidade Federal de Viçosa.

Walker, N.A.; Pitman, M.G. 1976. Measurement of fluxes across membranes. In: Encyclopedia of Plant Physiology, New Series. Berlin, Springer-Verlag. v.2A, p.93125. 